\title{
PLATAFORMAS Y APLICACIONES Nuevas tendencias para la economía digital
}

\author{
Platforms and Applications \\ New Trends for the Digital Economy
}

Juan Cruz Vallefín I juancruzvallefin@hotmail.com

Facultad de Bellas Artes. Universidad Nacional de La Plata. Argentina

Reseña a Nick Srnicek (2018). Capitalismo de Plataformas. Ciudad Autónoma de Buenos Aires, Argentina: Caja Negra Editora.

126 páginas

Recibido: 6/2/2019 Aceptado: 14/5/2019

\section{RESUMEN}

En la siguiente reseña se señalan los aciertos de Nick Srnicek al postular un capitalismo de plataformas junto con las limitaciones metodológicas que implica centrarse en el accionar del capital en vez de la fuerza de trabajo social. Asimismo, se indican posibles recorridos teóricos a realizarse - tanto a nivel laboral como político-, enfocando el análisis desde el trabajo en vez del capital como principio metodológico.

\section{PALABRAS CLAVE}

Plataformas; economía digital; filosofía; comunicación

\begin{abstract}
The following review highlights the success of Nick Srnicek in applying a capitalism of platforms together with the methodological limitations involved in focusing on the action of capital instead of the social workforce. Possible theoretical routes are also indicated - both at the labor and political levels-, focusing the analysis from work instead of capital as a methodological principle.
\end{abstract}

\section{KEYWORDS}

Platforms; digital economy; philosophy; communication 
Nick Srnicek en su libro Capitalismo de plataformas (2018) plantea el argumento de que las plataformas digitales -Facebook, Google, Uber- son un nuevo modelo de acumulación centrado en la extracción y el uso de datos. Este vuelco por parte del capitalismo avanzado tendría su origen histórico en la recesión global de los años setenta que el autor enfoca desde los términos primer-mundistas sobreproducción o tasas bajas de interés fijo. Manifiesta, así, el lugar desde el que enuncia, ya que no menciona su correlato dialéctico tercermundista: desmantelamiento de industrias y endeudamiento internacional con altas tasas de interés compuesto y simple, lo que delata el esquema difusionista de la historia que maneja, profundamente teleológico y eurocéntrico. ${ }^{1}$

A pesar de esta desestimación de las tres cuartas partes del mundo en el desarrollo y la aplicación de plataformas digitales, ${ }^{2}$ el libro tiene un gran acierto al describir sus características y principios dentro de un marco categorial lógico. De ese modo, demuestra una gran capacidad de abstracción, acierto que, sin embargo, constituye a la vez su mayor defecto, porque al centrarse - por cuestiones metodológicas sumamente tendenciosas- en el accionar del capital en vez de hacerlo en el del trabajo, ${ }^{3}$ quedan insalvablemente desdibujadas las relaciones sociales en íntima relación con las fuerzas de producción.

Por ejemplo, si analizamos PedidosYa y Glovo desde el capital, nuestro estudio se reduciría a una cuestión de gestión, eficacia o competitividad empresarial. Si el mismo caso es tomado desde la perspectiva laboral, la presencia de contratos en la primera acorde al modelo progresista del país oriental y la ausencia de toda conexión empresatrabajador en la segunda como consecuencia de la crisis económica española, descubrimos en las plataformas una huella laboral dentro de su aparente virtualidad. ${ }^{4}$

A Srnicek, en definitiva, se le puede aplicar la crítica que Karl Marx (1975) le realizó a PierreJoseph Proudhon:

\begin{abstract}
[...] el economista ha sabido ver muy bien que los hombres hacen el paño, el lienzo, la seda, en el marco de relaciones determinadas de producción. Pero lo que no ha sabido ver es que estas relaciones sociales determinadas son producidas por los hombres lo mismo que el lienzo, el lino, etcétera (p. 68).
\end{abstract}

Srnicek estudia las plataformas digitales desde un enfoque superficial, sin calcular el área de efectos que posee en los distintos relatos locales, ya sea en el plano laboral por medio de la flexibilización -eufemismo de la desregulación jurídica一, o en el plano político, a través del fenómeno conocido como Big Data. Este hecho resulta sumamente consecuente con su particular visión del capital, plasmada en el manifiesto Aceleracionista (1990) del que fue coautor con Alex Williams.

La conclusión del libro propone la creación de plataformas públicas -que sean propiedad del puebloy estén controladas por él-e independientes de la vigilancia del Estado, experiencia que si en el contexto de Reino Unido es utópica, en nuestro país fue posible mediante el Plan Conectar Igualdad del 2010 -cerrado por decreto en el 2016- . En definitiva, solo devolviéndole la primacía de análisis al trabajo en distintos estados -o fuerza de trabajo social comparado en términos marxianos- las categorías se materializan y las plataformas virtuales se anclan en la realidad histórica que las produjo.

\section{REFERENCIAS}

Avanessian, A. y Reis, M. (Comps.). (2013). Aceleracionismo. Estrategias para una transición hacia el postcapitalismo. Ciudad Autónoma de Buenos Aires, Argentina: Caja Negra Editora.

Dussel, E. (2007). Política de la liberación. Historia mundial y crítica. Madrid, España: Trotta.

Han, B. C. (2014). Psicopolítica: neoliberalismo y nuevas técnicas de poder. Madrid, España: Herder. 
Marx, K. (1975). Miseria de la filosofía: respuesta a la filosofía de la miseria de P.J. Proudhon. Ciudad de México, México: Siglo Veintiuno.

Srnicek, N. (2018). Capitalismo de Plataformas. Ciudad Autónoma de Buenos Aires, Argentina: Caja Negra Editora.

\section{NOTAS}

1 Para una crítica al esquema difusionista y eurocéntrico de la historia, léase Enrique Dussel (2007).

2 Desestimación inexacta en cuanto considera como plataformas trans-nacionales como si fuesen plataformas en sí, ignorando las diferencias que puedan surgir de modelos locales.

3 «Para algunos, poner el foco de esta manera en el capital en lugar del trabajo puede sugerir un vulgar economicismo; pero en un mundo en el que el movimiento de los trabajadores ha sido significativamente debilitado, dar al capital una prioridad de acción parece solo reflejar la realidad» (Srnicek, 2018).

4 Insistimos en que estas apps, pese a sus diferencias, poseen modelos basados en la flexibilidad e irregularidad. 5 El Aceleracionismo es una teoría de origen inglés que propone acelerar la evolución tecnológica del capitalismo para lograr fines poscapitalistas como la automatización del trabajo o la fusión de lo digital humano. 